\title{
THE INTERTWINEMENT OF PROPOSITIONAL AND DOXASTIC
}

\section{JUSTIFICATION}

\begin{abstract}
Giacomo Melis
University of Stirling

This is the accepted version of an article whose final and definitive form is published in the Australasian Journal of Philosophy. The Australasian Journal of Philosophy is available online at: http://www.tandf.co.uk/journals/. The article is available at the following permanent link: http://dx.doi.org/10.1080/00048402.2017.1342097. Please cite the published version only.
\end{abstract}

One important distinction in the debate over epistemic justification is the one between propositional and doxastic justification. Roughly, while doxastic justification is a property of beliefs, propositional justification is a property of propositions. On a rather common view, which accounts for doxastic justification in terms of propositional justification plus the socalled 'basing relation', propositional justification is seen as the prior notion, and doxastic justification is explained in terms of it. According to the opposing view, the direction of explanation needs to be reversed, and doxastic justification should be seen as primary. I distinguish between two notions of priority, and I argue that they give different verdicts with respect to the issue of which notion of justification comes first. The lesson may be taken to be that propositional and doxastic justification are in a relation of intertwinement.

Keywords: propositional justification; doxastic justification; conceptual priority; theoretical priority

\section{Preliminaries}


Let me begin by briefly explaining the notions of priority I will be working with, the distinction between propositional and doxastic justification, and the main heuristic presupposition of the paper.

Following Ichikawa and Jenkins [forthcoming: sec. 2], we can distinguish between metaphysical and representational families of priority. While representational priorities locate the priority in the way in which we think or talk about the relevant subject matter, metaphysical priorities locate the priority in something like the hierarchical structure of reality. One way to see the difference between the two families may be the following: if $G$ is representationally prior to $\mathrm{F}$, then cognitively engaging with $\mathrm{F}$ requires one to cognitively engage with $\mathrm{G}$ (while F-facts may not obtain in virtue of $\mathrm{G}$-facts) ${ }^{1}$ by contrast, if $\mathrm{G}$ is metaphysically prior to F, then F-facts obtain at least in part in virtue of G-facts (but cognitively engaging with $F$ needn't require one to cognitively engage with $G){ }^{2}$

The family that matters for the purposes of this paper is the representational one, and I wish to draw a further distinction within it. Say that a notion $\mathrm{F}$ has conceptual priority over a notion $\mathrm{G}$ when a previous grasp of $\mathrm{F}$ is required to grasp $\mathrm{G}$; on the other hand, a notion $\mathrm{F}$ has theoretical priority over a notion $\mathrm{G}$ when the role played by $\mathrm{G}$ in philosophical theorizing is, in some important sense, subordinate to the role played by F. While conceptual priority pertains to relations between concepts (and the order in which they may be grasped), theoretical priority pertains to relations between theoretical roles or statuses of concepts employed in a theory. These are the two notions of priority that I will discuss in the rest of the paper.

\footnotetext{
${ }^{1}$ Just a blunt example to drive the point home: Inspector Rebus can only find out about the details of the murder by cognitively engaging with the circumstantial evidence available, but the facts that constitute the details of the murder did not obtain in virtue of the circumstantial evidence.

${ }^{2}$ For example, facts about biology obtain at least in part in virtue of facts about physics, and yet one can cognitively engage with biology without having to cognitively engage with physics.
} 
Let's now come to the propositional/doxastic distinction. It is customary to introduce the distinction in the following way: when a subject has some reasons to believe a proposition, she has propositional justification to believe that proposition; when a subject has some reasons to believe a proposition, and bases her belief on those reasons, she is doxastically justified in believing that proposition. ${ }^{34}$ Here's a quick example. Someone who has a reason to believe both that Pablo Neruda was Chilean, and that if Pablo Neruda was Chilean, then he was from South America, has (propositional) justification to believe that Pablo Neruda was from South America. However, it's not until one draws the relevant inference that one becomes (doxastically) justified in believing that Pablo Neruda was from South America. On the other hand, if the agent just described formed the belief that Pablo Neruda was from South America out of wishful thinking, she would fail to be doxastically justified in believing the proposition in question despite having propositional justification to believe it. $^{5}$

So, doxastic justification can be characterized as propositional justification plus the obtaining of a basing relation (between propositional justification and the relevant belief). ${ }^{6}$ This common way of drawing the distinction makes it easy to appreciate that doxastic justification entails propositional justification but not vice versa. Such entailment relation, and the distinction between conceptual and theoretical priority, will be our starting points. Before getting started, however, another important preliminary consideration is in order.

\footnotetext{
${ }^{3}$ See Feldman [2003: 46], Pollock and Cruz [1999: 35-6], and Lasonen-Aarnio [2010: 205-6] for just some of the many examples of this way of drawing the distinction. The distinction, and indeed the choice of the terms 'propositional' and 'doxastic' goes back at least to Firth [1978: 218].

${ }^{4}$ I use the preposition 'to' to refer to propositional justification (as in ' $S$ is justified to believe that $p$ '), and the preposition 'in' to refer to doxastic justification (as in ' $S$ is justified in believing that $p$ ').

${ }^{5}$ As an anonymous referee helpfully observed, one can have propositional justification to believe $p$ and yet fail to be doxastically justified in believing $p$ in at least two different ways: one might fail to form the belief that $p$, or one might fail to base it on the relevant reasons.

${ }^{6}$ Turri [2010: sec. 2] argues that propositional justification plus the basing relation is not sufficient for doxastic justification. In addition, he contends, the agent has to use the basis in the right way. While this much seems right, there is no need to discuss Turri's examples for the present purposes. For more on the debate raised by Turri's influential paper see footnote 12 below.
} 
Philosophers seem to adopt as their working notion either propositional or doxastic justification, depending on the perspective from which they look at epistemic justification. While those who, like Goldman [1979] or Kornblith [1980], focus on matters of beliefformation tend to theorize about doxastic justification, those who, like Conee and Feldman [1985] or Kvanvig [2007], tend to conceive of justification as a relation between propositional contents normally advance theories about propositional justification. Yet, both strands of epistemological theorizing attempt to provide a theory of the same thing: namely, epistemic justification. It is thus natural to think that the two notions of justification have a common nature and, at the same time, wonder about the relationship between them, including the question whether one of the two is more fundamental, or has priority over the other. Among other things, one reason why the issue matters is that showing that one of the two notions is more fundamental than the other may provide support to the claim that one of the two broad approaches to doing epistemology just mentioned cuts deeper at the heart of the discipline, as it were.

In addressing the issue of priority, it is vital not to lose sight of the thought that the two notions have a common nature. To achieve that, it is at least heuristically important to have the backdrop of a broad characterization of epistemic justification so that a common ground between opposing views is established, and a neutral vantage point to impartially assess different positions is reached. To attain the common ground, I propose to conceive of epistemic justification in terms of epistemic reasons, and to simply characterize such reasons as any of the many factors that may play the justificatory role according to the various theories of justification. Thus I will use the expression 'epistemic reasons' (or just 'reasons') as a placeholder for a variety of justifying factors such as, for example, the evidence available to the subject, the reliability of the process by which the belief was formed, or the coherence of a proposition with a larger set of propositions. In speaking of epistemic reasons, I thus 
intend to remain neutral on what exactly those reasons may be in the specific case. By doing so, I aim to avoid the risk of theoretically overloading the notions of propositional or doxastic justification in a way that may stack the deck in favour of the priority of one of the two notions. For the overarching purposes of this paper, what distinguishes propositional and doxastic justification is simply that the latter entails belief while the former does not. ${ }^{7}$

However, for ease of discussion, in the two main sections that follow I will focus on two specific characterization of propositional and doxastic justification. That shouldn't obfuscate the fact that I will be trying to look at the difference between the two notions from a neutral standpoint. ${ }^{8}$

\section{Conceptual Priority}

I said that doxastic justification entails propositional justification but not vice versa. It might be tempting to argue that such entailment relation is explained by the fact that we conceptualize doxastic justification as the conjunction of propositional justification and the basing relation, and that, since conjuncts have conceptual priority over the conjunction in which they appear, propositional justification has conceptual priority over doxastic justification. ${ }^{9}$

However, it may be objected that a conjunct can only be said to be conceptually prior to the conjunction in which it appears if it can be specified without any reference, explicit or implicit, to the notion expressed by the conjunction as a whole. ${ }^{10}$ Otherwise, the characterization of the notion that is supposed to be conceptually prior (a conjunct) would

\footnotetext{
${ }^{7}$ I take it that this is also what grounds the distinction in ordinary discourse: for example, it would seem that when one criticizes a creationist for failing to believe that dinosaurs existed despite all the fossil evidence available, one is criticizing the creationist for failing to be doxastically justified in believing that dinosaurs existed despite having propositional justification to that effect.

${ }^{8}$ The reasons for my choices in the next two sections are explained in footnotes 13, 23, and 24 below.

${ }^{9}$ A suggestion along these lines can be found in Fumerton [2006: 36]. Kvanvig and Menzel [1990] may not have explicitly mentioned conceptual priority, but have defended the priority of propositional justification as a result of the consideration that doxastic justification equals propositional justification plus basing. See Turri [2010: 313-4] for a more comprehensive list of philosophers who have argued along similar lines.

${ }^{10}$ Williamson [2000: 3] makes a similar point in a different discussion.
} 
appeal to the notion that is supposed to be characterized in terms of it (the conjunction), and it couldn't be conceptually prior. If propositional justification is conceptually prior to doxastic justification, we should be able to characterize it without explicitly or implicitly referring to doxastic justification.

The problem is that it's not clear whether this can be done. If philosophers like Bergmann [2006: 4] and Turri [2010: 320] are right, the notion of propositional justification is grasped with the help of the notion of doxastic justification. More precisely, the suggestion is that a subject has justification to believe a proposition when she's got reasons such that were she to base her belief in that proposition on those reasons, she would be doxastically justified. ${ }^{11} 12$ If so, propositional justification is, at bottom, potential doxastic justification, and it does not enjoy conceptual priority over doxastic justification.

To repeat: a defence of the conceptual priority of propositional justification has to face the task of showing that propositional justification can be characterized without appealing, explicitly or implicitly, to doxastic justification. Can that be done?

For the sake of simplicity, let us limit the discussion to one characterization of propositional justification that seems well placed to achieve the result. Consider how propositional justification may be described within the popular framework according to which epistemic justification is understood in terms of evidential likelihood:

\footnotetext{
${ }^{11}$ Similar claims had already been advanced by Goldman [1979: 345], Alston [1985: 104], and considered by Firth [1978: 220]. Zardini [2014: 34] introduces the distinction between propositional and doxastic justification in the same way.

${ }^{12}$ As recalled in footnote 6, Turri argues that propositional justification plus the obtaining of the basing relation is not sufficient for doxastic justification. Through the discussion of some examples, he goes on to draw the lesson that it is a mistake to endorse the orthodox explanation of doxastic justification in terms of propositional justification. Silva [2015] argues that the problem for the orthodox account highlighted by Turri is amenable to a rather straightforward solution. While this paper does not engage with Turri's or Silva's examples, the present section may be described as aiming to vindicate what's appealing in Turri's suggestion, and section 3 may be broadly portrayed as an attempt to defend the orthodoxy attacked by Turri. See Vahid [2016: sec. 1] for an overview of the debate on Turri's paper.
} 
A subject $S$ has justification to believe $p$ on account of some evidence $e$ when there is a strong probabilistic connection between $e$ and $p$ : namely, the truth of $e$ makes the truth of $p$ very likely. ${ }^{13}$

It would seem that no appeal to doxastic justification is needed to understand the notion of strong probabilistic connection. If that is right, we may have a way to characterize propositional justification without appealing to doxastic justification.

One objection to this suggestion is that if we take a strong probabilistic connection between $e$ and $p$ as sufficient for propositional justification, then a subject that has justification to believe $p$, has also justification to believe all the unseen or remote probabilistic consequences of $p$. This may look like a bad result: despite the strong —indeed, maximal—probabilistic connection between Peano's axioms and Fermat's Last Theorem, it seems counterintuitive to say that an agent who has justification to believe Peano's axioms also has justification to believe Fermat's Last Theorem. ${ }^{14}$

To avoid the objection, one might suggest adding the clause that the agent needs to be able to grasp the probabilistic connection between $e$ and $p$, on top of there just being one. Other worries aside, ${ }^{15}$ it doesn't look as though such a reply can be helpful for the present purposes: an agent who can grasp the strong probabilistic connection between $e$ and $p$ is an agent who's in the position to form a justified belief in $p$ on the basis of $e .{ }^{16}$ And to the extent that the connection between $e$ and $p$ is an evidential relation, being in the position to grasp it

\footnotetext{
${ }^{13}$ Let me emphasize again that I intend to remain neutral on what the best characterization of propositional justification is. The only reason I am choosing to discuss the characterization in terms of evidential likelihood in this section is that, on the face of it, it is rather promising with respect to the task at hand-namely, describing propositional justification without appealing, at some level, to doxastic justification.

${ }^{14} \mathrm{~A}$ worry along these lines is raised in Boghossian [2014: sec. 5], and Turri [2010: 321-2].

${ }^{15}$ One concern here is that such a move over-intellectualizes the situation. Since some agents seem to form justified beliefs without any grasp of the relevant relation of epistemic support- - think about justified beliefs of very young children, for example - we might wonder whether a notion of propositional justification that imposes the requirement that the agent needs to be able to grasp the support relation between $e$ and $p$ can apply to all intended agents. For an early complaint along these lines, see Alston [1983: 84ff].

${ }^{16}$ Assuming the agent possesses $e$ in the first place.
} 
may be taken to involve appreciating that one would be warranted to form a belief in $p$ on the basis of $e$ : arguably, the very notion of evidence involves reference to some agent for whom a piece of evidence would support some attitude. ${ }^{17}$ If so, this way of replying to the objection seems to reveal that the characterization of propositional justification provided appeals - at least implicitly — to the notion of (potential) doxastic justification.

The advocate of the conceptual priority of propositional justification might want to take a step back at this stage, and observe that, in an interesting sense, the ordinary agent who has justification to believe Peano's axioms has justification to believe Fermat's Last Theorem too; it's just a pity that she's not able to avail herself of it. The notion of justification invoked here is one that extends beyond the limits of the subject's cognitive or doxastic capacitiesthe underlying suggestion being that epistemic justification can be understood as a source of evaluative ideals that we should do our best to achieve, rather than as a source of obligatory tasks that we ought to achieve. If so, propositional justification applies primarily to strongly idealized subjects—-subjects able to derive Fermat's Last Theorem from Peano's axioms. A view along these lines has been recently defended, for example, by Smithies [2012: sec. 2], and Ichikawa and Jarvis [2013: 163]. ${ }^{18}$

Let's call the notion of justification just sketched 'objective propositional justification'. Following Ichikawa and Jarvis [ibid.], let's agree that it 'concerns the objective degree of support that a subject's evidence confers on a proposition.' Roughly speaking, we might suggest that the weaker notion - the one that sets only achievable goals, and that we might now call 'ordinary propositional justification' — can be understood as flowing from it. We might say that the subject has objective propositional justification to believe all the propositions that are probabilistically supported to the required degree by the evidence at her

\footnotetext{
${ }^{17}$ More on this point in a minute: see the upcoming discussion on the thought that evidence can be evidence only for some epistemic agent.

${ }^{18}$ See also Conee and Feldman [1985: 86-7].
} 
disposal, but that she's got ordinary propositional justification only for the subset of propositions that her cognitive and doxastic abilities enable her to believe with justification. We have thus distinguished two notions of propositional justification. ${ }^{19}$ But let us go back to the issue of conceptual priority: can objective propositional justification be conceptually prior to doxastic justification?

It does not look like it. To see why, we need to reflect on the fact that the notion of probability in play in the characterization of (the evidential support involved in) objective propositional justification is an epistemic one: it is probability measured relatively to a body of evidence. I have called it 'objective' only in the sense that it is not constrained by the subject's cognitive or doxastic limits, but it remains constrained by the delimitation of a body of evidence $e$ over which the probability of the relevant $p$ has to be determined.

But arguably, evidence can be evidence only for some epistemic agent: it would seem that the very notion of evidence presupposes that there is some subject for whom a given piece of information speaks (or would speak) in favour of some proposition $p$. While it might not be very clear what exactly counts as evidence (propositions, events, objects, experiences . .. ), it seems clear that whatever counts as evidence is something that, when possessed by $a$ subject, supports a given attitude (belief, disbelief, suspension, some credence) of that subject towards a proposition $p$. Of course, the relevant notion of subject is very wide here: the subject in possession of the evidence needn't be an ordinary human being, but it may be the extremely idealized agent who has infinite logical power and can see the link between Peano's axiom and Fermat's last theorem, or even a collective agent (say, the scientific

\footnotetext{
${ }^{19}$ The two notions of propositional justification have also been distinguished in Ichikawa and Jarvis [2013: 163] and Coliva [2014: 254]. However, the terms used to describe the properties differ. What I call 'objective propositional justification' is called simply 'propositional justification' by Ichikawa and Jarvis, and simply 'propositional warrant' by Coliva. What I call 'ordinary propositional justification' is called 'ex-ante justification' by Ichikawa and Jarvis, and 'warrant that is available to the subject' by Coliva. In general, there seems to be some terminological confusion in the literature: contrary to Ichikawa and Jarvis and Coliva, some philosophers, like Boghossian [2014] and Turri [2010] use the expression 'propositional justification' to refer to what I call 'ordinary propositional justification'.
} 
community). But what seems to make no sense is to talk of evidence for no agent

whatsoever - that is, evidence that does not rely on the idea that if some agent were in possession of it, then that agent would be under pressure to adopt some doxastic attitude towards some proposition. As Kelly [2016: sec. 1, emphasis mine] puts it: 'evidence, whatever else it is, is the kind of thing which can make a difference to what one is justified in believing or ... what is reasonable for one to believe.'

If the foregoing goes along the right lines, what makes a piece of information a piece of evidence is the fact that an agent—no matter how idealized—-takes it (or can take it) to support the truth of some proposition. Otherwise, a piece of information is just a piece of information. Surely, that piece of information will be statistically related to another, but a statistical relation, in and of itself, is not an evidential relation. Not yet, at least. It's only when some epistemic agent — again, even just a highly idealized one — reads a statistical relation as an evidential relation that a statistical relation becomes an evidential relation. It's the epistemic agent, loaded with her own background information and specific epistemic goal(s), who determines which proposition (say, of the two that are statistically related) is evidence for which. ${ }^{20}$ If so, the probabilistic support that $e$ gives to $p$ in the proposed characterization of propositional justification is a measure of some agent's degree of justification to believe $p$.

And when does such agent have justification to believe $p$ ? When she's got reasons such that if she were to believe $p$ and base her belief that $p$ on those reasons, she would be justified in believing that $p$. But that's potential doxastic justification, and being potential doxastic justification for a highly idealized subject does not make it less so. As Smithies

\footnotetext{
${ }^{20}$ Here's an example. Suppose that there is a strong statistical correlation between ' $S$ speaks good English' and ' $S$ is British'. For an agent who, through a quick chat, is trying to identify the British citizens in a group of mixed nationalities, the first proposition may be good evidence for the second; for an agent who is trying to figure out who might speak English by reading details about the members of the mixed group on some document, the second proposition may be good evidence for the first.
} 
[2012: 280] acknowledges, 'the propositions that one has justification to believe are those propositions that one would believe if one were to be idealized in relevant respects.' If so, the conclusion seems to be that a grasp of the notion of doxastic justification is needed to grasp the notion of propositional justification. If that is right, propositional justification is not conceptually prior to doxastic justification.

To sum up, we may think that grasping the notion of objective propositional justification needs to appeal to doxastic justification because it requires appealing to an idealized agent who, from her own epistemic perspective, can tell what piece of information is evidence for another. The directionality that is needed by the evidential relation (in virtue of which $e$ can be said to be evidence for $p$ rather than the other way round) is something that can only be provided by an agent — no matter how idealized we take it to be. Indeed, as the example made in footnote 20 should make clear, the same point applies with respect to ordinary propositional justification. The upshot seems to be that understanding what propositional justification is relies on imagining some sort of agent that could, would, or should believe the proposition in question. Propositional justification does not appear to have conceptual priority over doxastic justification.

But what about those (objective) Bayesian accounts of propositional justification that explicitly reject the idea that evidential probability boils down to the credences of a perfectly rational agent in possession of the relevant evidence, such as the one advanced by Williamson [2000: ch. 10]? It's not clear that someone who sympathizes with such Bayesian accounts would be persuaded by the foregoing considerations. More generally, how do the foregoing considerations bear upon such accounts of propositional justification?

It is important to realize that I'm not suggesting that the foregoing considerations show that an appeal to an ideal agent (and thus an appeal to potential doxastic justification) is needed to develop a theory of propositional justification in terms of probability. That would 
be to suggest that doxastic justification enjoys theoretical priority, and I will deal with theoretical priority only in the next section. What the discussion of this section shows is rather that an appeal to an ideal agent (and thus a grasp of the notion of doxastic justification) is needed to come to terms with the notion of propositional justification itself, before the theory of propositional justification in terms of probability is even sketched. We may say that an appeal to doxastic justification is needed to explain what a theory of propositional justification in terms of evidential probability is a theory of, but the appeal to doxastic justification needn't be part of the theory itself. ${ }^{21}$ In other words, even if we decide to account for propositional justification in terms of abstract relations between propositions, in explaining what those abstract relations and propositions are a theory of, we'll need to appeal to some agent for whom those relations would obtain. Thus, the claim that doxastic justification has conceptual priority over propositional justification is not meant to be in tension with probabilistic accounts of propositional justification that do not rely, in the theory itself, on the notion of ideal rational agent.

In short, understanding what a Bayesian account of propositional justification is in the first place requires appealing to some agent engaged in the project of forming true beliefs, and this suggests that even Bayesianism has to bow to the conceptual priority of doxastic justification, as it were. Importantly, that's not to deny that a Bayesian account of the propositions that are supported by one's evidence may be given without reference to the beliefs that those relations would support. As already noted, the appeal to such beliefs may be made outside of the theory, and it's only needed to grasp what the theory is a theory ofnamely, epistemic justification — without actually playing a role in the theory itself. To my mind, this speaks in favour of the conceptual priority of doxastic justification. At the same

\footnotetext{
${ }^{21}$ That is why I did not have to engage with any specific probabilistic theory of justification in order to make the point.
} 
time, it may suggest that the relation of priority could be reversed when we turn to theoretical priority, but let us not anticipate things.

At this stage, one may observe that even if what has been said so far is broadly right, it still does not establish the conceptual priority of doxastic justification. To do so, what is needed is a characterization of doxastic justification which does not appeal, even implicitly, to propositional justification. I shall not attempt the task here, but I think there are reasons to be optimistic about the project. Consider the following.

One of the things that the foregoing discussion might be taken to suggest is that, broadly speaking, the notion of doxastic justification is a development of the notion of actual justified belief, and that, in turn, the notion of propositional justification is a development of the notion of potential justified belief. Now, to the extent that grasp of the notion of an actual $\mathrm{G}$ can be had prior to, and independently of, a grasp of the notion of a potential G, doxastic justification can be grasped prior to, and independently of, propositional justification. Just like we can understand what it means to speak English independently of understanding what it means to have the potential to speak English, or we can understand what it means to be a professional football player independently of understanding what it means to have the potential to become a professional football player, we can presumably understand what it means to have a justified belief (doxastic justification) independently of understanding what it means to have a potential justified belief (propositional justification).

If the foregoing is along the right lines, we have some reasons to expect that doxastic justification can be shown to be conceptually prior to propositional justification, but not vice versa.

One may further object that I have not shown that the point holds if we opt for characterizations of propositional justification other than the one in terms of evidential likelihood. Agreed: it is beyond the scope of this paper to offer a discussion of all possible 
notions of propositional (and indeed doxastic) justification. The goal of the section was to offer some initial motivation for the view that doxastic justification enjoys conceptual priority by showing that one notion of propositional justification that seemed well placed to be broadly characterized without any implicit appeal to doxastic justification, under closer inspection, does seem to rely on doxastic justification.

\section{Theoretical Priority}

When we turn our attention to theoretical priority, however, the order of priority appears to differ. In the first section I suggested that a notion $\mathrm{F}$ has theoretical priority over a notion $\mathrm{G}$ when the role played by $\mathrm{G}$ in philosophical theorizing is subordinate to - or at any rate depends on - the role played by F. Recall that while conceptual priority pertains to relations between concepts, theoretical priority pertains to relations between roles of concepts in a theory. What seems clear is that theoretical priority does not entail conceptual priority. ${ }^{22}$ If the present investigation moves along right lines, the case of the relation between propositional and doxastic justification reveals that conceptual priority does not entail theoretical priority either.

To suggest that propositional justification has theoretical priority over doxastic justification is to say that a theory of the beliefs that one is justified in holding relies (maybe only implicitly) on an a theory of the propositions that are supported by one's reasons, regardless of, and prior to, whether one goes on to form the relevant beliefs or not. ${ }^{23}$

\footnotetext{
${ }^{22}$ For example, the concept of steering wheel has theoretical priority over the notion of turning in a theory of car driving (the theory will say that one has to operate the steering wheel in order to turn the car), but it is not conceptually prior to it (one can grasp the notion of turning without grasping the notion of steering wheel). Similarly, as we saw in the previous section, a Bayesian theory might assign theoretical priority to propositional justification, but that doesn't show that propositional justification also enjoys conceptual priority.

${ }^{23}$ At the risk of coming across as pedantic, let me recall that the relevant notion of reasons is very broad. I do not wish to suggest that propositional justification is in this section still to be understood in terms of evidential likelihood. Rather, at this stage it should be understood in the most theoretically neutral way: namely, as the justification that does not entail belief (regardless of what general theory of epistemic justification one might favour). The characterization of justification in terms of evidential likelihood was only adopted for the purposes of section 2 and, as it will be clear soon, for the purposes of section 3 it will be helpful to adopt a different view of justification.
} 
Examples of theories that grant theoretical priority to propositional justification are provided by Kvanvig's propositionalism, or by Conee's and Feldman's evidentialism. Such theories take their main goal to be that of describing the relation of evidential support holding between propositional contents, and account for the beliefs that are justified for one by appealing to the relation of evidential support holding between propositions. Thus, in Kvanvig's propositionalism and Conee's and Feldman's evidentialism the theoretical priority of propositional justification is part of the programmatic approach.

But the issue that matters for our purposes is whether the theoretical priority of propositional justification is imposed by the subject matter, as it were. The interesting question is whether all satisfactory accounts of the beliefs that one is justified in holding have to rely, at some point, on an account of what propositions are supported by one's reasons.

One may want to argue for the theoretical priority of propositional justification on the grounds that propositional justification enjoys metaphysical priority-in the sense described in section $1-$ over doxastic justification. Focusing on an evidentialist account of justification, one might suggest that, since one can only base a belief in $p$ on the basis of evidence $e$ if one has got $e$ in the first place, doxastic-justification-facts (roughly, facts about the use of some evidence $e$ in forming the belief that $p$ ) obtain in part in virtue of propositional-justificationfacts (roughly, facts about evidence possession). If so, one may argue that any adequate theory of doxastic justification has to respect this feature and at bottom rely in some way on a theory of propositional justification. Tempting as this line of argument might be, it cannot serve the present purposes.

First of all, it relies on a theoretically loaded general characterization of justification in terms of evidence, but as we already observed, one needn't characterize epistemic justification in terms of evidence. Thus, a way of establishing the theoretical priority of propositional justification relying on an evidentialist account of justification would not have 
the general significance that we are looking for. We are looking for some initial reason to believe that all accounts of doxastic justification have to rely, at some point, on propositional justification, not just that there is one account that does so (and it would be rather unsurprising that an evidentialist account of justification delivers that result). ${ }^{24}$ Secondly, it is not in general the case that a metaphysical notion of priority determines a corresponding representational priority: it's at least conceivable that even if doxastic-justification facts occur at least in part in virtue of propositional-justification facts, an account of what beliefs one is justified in holding needn't rely on an account of what propositions one has justification to believe. $^{25}$

I have to admit that I do not have an argument to the effect that, in general, propositional justification is theoretically prior to doxastic justification. Once again, we'll have to make do with considerations providing some abductive reasons for optimism. My suggestion is that the likely theoretical priority of propositional justification may be defended by recalling how one important theory of epistemic justification that started with the ambition of accounting for doxastic justification independently of propositional justification had to, at one point, appeal to propositional justification in order to accomplish its task.

\footnotetext{
${ }^{24}$ Note, however, that the focus on the evidentialist account in the previous section was warranted: had we found that the broad evidentialist view considered could vindicate the conceptual priority of propositional justification, we would have falsified the claim that all general characterizations of justification assign conceptual priority to doxastic justification. That was the claim under investigation in the previous section, and the focus on evidentialism was due to the fact that it offered a prima facie good candidate to deliver that result. By contrast, in this section, the claim that we will be trying to falsify is that all general characterization of justification assign theoretical priority to propositional justification, and we will work with a general account of justification that has at least some prima facie credibility to successfully carry out the task: namely, reliabilism. ${ }^{25}$ As suggested in Section 1, it is not obvious that the way in which we think or talk about reality (or about a specific subject matter) should mirror the hierarchical relations that hold in reality itself. If so, metaphysical priority, in and of itself, does not guarantee representational priority (see footnote 2). And since I have characterized theoretical priority as a species of representational priority, the theoretical priority of propositional justification over doxastic justification would not merely follow from establishing that propositional justification has metaphysical priority.

While a discussion of metaphysical priority goes beyond the scope of this paper, it is worthwhile noting that the view recently explored in Vahid [2016] — according to which propositional justification is a dispositional property and doxastic justification its manifestation-may be seen as ascribing metaphysical priority to propositional justification (to the extent that the relation between a disposition and the occurrence of the relevant manifestation is characterized as distinctively metaphysical in nature). See Ichikawa and Jenkins [forthcoming: secs 3-4] for some discussion of the relationship between the two main families of priority.
} 
The theory I am alluding at is Goldman's process-reliabilism. Here are two telling passages from Goldman's declaration of intent:

The aim of this essay is to sketch a theory of justified belief ..., one that explains in a general way why certain beliefs are counted as justified and other as unjustified.

I do not even assume that when a belief is justified there is something 'possessed' by the believer which can be called a 'justification'.

[Ibid.: 334]

On the face of it, Goldman sets out to provide a theory of doxastic justification which is independent of a theory of propositional justification. Let's see how, despite the original stated goal, Goldman comes to acknowledge the crucial theoretical role played by propositional justification.

Broadly speaking, process-reliabilism has it that a belief is justified in case it is caused by a process that is actually reliable, or that it is generally believed to be reliable. Thus, the theory has a diachronic understanding of justification: the justificational status of a belief depends on its causal history. Now, to the extent that propositional justification is often characterized within a synchronic framework - the justificational status of a proposition is commonly taken to depend entirely on the reasons available to the subject at a given time $t$ one might wonder whether reliabilism can account for propositional justification at all. After all, propositional justification is commonly described as something that is possessed by the subject (typically exemplified by a piece of evidence), and it's not clear what the subject can be said to possess in a diachronic account of justification: belief-forming processes are not the sort of thing that one can possess. 
Of course, reliabilism can account for propositional justification. Such justification is better described as being available to-rather than as being possessed by — the subject. We can say that a subject $S$ has justification to believe a proposition $p$ when there is a reliable belief-forming process or operation available to $S$ such that if $S$ applied that operation to her cognitive state at time $t$, she would be justified in believing $p$ at time $t_{+n}$ [Ibid.: 345]. ${ }^{26}{ }^{27}$ It's worth stopping a moment on this characterization of propositional justification to make sure we avoid possible confusions.

One might worry that, to the extent that belief-forming processes are something broadly psychological, the availability of a belief-forming process supporting a given proposition $p$ cannot really be used to characterize propositional justification. Rather, the notion of available reliable belief-forming process that would lead one to believe $p$ should be seen as an alternative (though counterfactual) doxastic justification. But remember that in section 1 we agreed that our neutral vantage point requires us to conceive of propositional justification as simply the justification that does not entail (actual) belief. ${ }^{28}$ And within a reliabilist framework that is the justification provided by a merely available (that is, not actually used) belief-forming process. Thus, the objection that a merely available beliefforming process cannot be considered a kind of propositional justification because it is a broadly psychological notion relies on assumptions about the nature of propositional justification $^{29}$ that go beyond what we are warranted to accept in the present context of

\footnotetext{
${ }^{26}$ This is something very similar to what an advocate of the conceptual priority of doxastic justification says propositional justification is; compare Bergmann's and Turri's suggestion mentioned in section 2 above. ${ }^{27}$ One might wonder what it is for a belief-forming process to be available to the subject. Goldman himself admits that the issue is somewhat vague, but there seem to be some good examples. Suppose that, whilst having a conversation with someone, you are distractedly watching a dog playing with a ball in the park. As it happens, you do not form any belief about the dog, but since you are looking at it, there is a clear sense in which you have propositional justification to believe that there is a dog playing in the park: the proposition 'there is a dog playing in the park' is within reach of a reliable belief-forming process of yours (which involves vision). ${ }^{28}$ Indeed, Goldman himself [2008: 64] draws the distinction between propositional and doxastic justification in these terms.

${ }^{29}$ Such as, for example, that propositional justification needs to be understood as an abstract relation between propositions.
} 
theoretical neutrality: namely, that propositional justification is that kind of justification that does not entail belief. With that in mind, there should be no further objections to the proposed reliabilist account of propositional justification. ${ }^{30}$

But in order to defend the theoretical priority of propositional justification, we have to show that reliabilism needs to rely on an account of propositional justification, not just that it can provide one.

Consider the following hypothetical scenario. Suppose that the subject $S$ is told-say, for the sake of some experiment - by an eye-doctor that her vision is not functioning well, while in fact $S$ 's vision is working fine. Suppose further that, despite the information acquired from the doctor, out of stubbornness, $S$ keeps believing what her vision suggests to be the case. Since $S$ 's vision is actually working fine, the beliefs in question are caused by a reliable process. Thus, the simple reliabilist theory presented above predicts that they are justified. However, since $S$ blatantly ignores some prima facie good reasons to distrust her vision-the eye-doctor's words-intuitively, those beliefs are not held in good intellectual conscience, and shouldn't count as justified (cf. Goldman [1979: 343-4]).

To reply to an objection along these very lines, Goldman proposed the following reelaboration of reliabilism: if the agent's belief that $p$ at $t$ is produced by a reliable process, and there is no reliable process available to the agent such that, if it had been used in addition to the process actually used, it would have resulted in the agent not believing $p$ at $t$, then the agent's belief that $p$ is justified [ibid.].

Back to the example: since there is a reliable process that, if used, would have resulted in S's not believing what her vision suggested—say, the process of recalling what

\footnotetext{
${ }^{30}$ See Turri [2010], and the references offered in footnote 11 for very similar characterizations of propositional justification. See also Becker [sec. 2.a] for the attribution of the propositional/doxastic distinction to Goldman.
} 
was previously said by the doctor - the refined version of reliabilism does not predict that $S$ 's visual beliefs are justified.

What's important for our purposes is that the overall lesson of the example, and of the proposed refinement of reliabilism that follows it, is that —as Goldman [ibid.] himself acknowledges - an account of what beliefs are actually justified depends also on an account of what beliefs could, and should, have been justified. In other words, doxastic justification theoretically depends on propositional justification. Or at least, we have some good prima facie reasons to think that it does.

\section{Conclusion}

I have offered some reasons to think that while propositional justification enjoys theoretical priority, doxastic justification has conceptual priority. So, in different senses, both the advocates of the priority of propositional justification and the advocates of the priority of doxastic justification are right. Since the two notions of priority here discussed concern both the way in which we think and talk about a given subject matter-they belong to what Ichikawa and Jenkins call 'representational families' of priority —we may think that, with respect to the question of how we think and talk about epistemic justification, propositional and doxastic justification stand in a relation of intertwinement. If so, neither notion can be properly said to have priority over the other without some clarifications along the lines that have been proposed in this paper. If I were to summarize the point of the article in one sentence, I'd say: while an appeal to doxastic justification seems to be needed to explain or understand what a theory of propositional justification even is, a theory of doxastic justification that ignores propositional justification would seem to fail to account for some crucial aspects of epistemic justification.

While the present paper offers some initial motivation for the combination of views proposed, it does not conclusively establishes that doxastic justification enjoys conceptually 
priority while propositional justification has theoretical priority. However, it does show that two characterizations of propositional and doxastic justification that might be at first taken to falsify the combination of views sketched, under close scrutiny, fail to do so.

\section{ACKNOWLEDGEMENTS}

I would like to thank Carrie I. Jenkins, Crispin Wright, Jonathan J. Ichikawa, and Jim Pryor for discussion. The article has also benefitted from the feedback provided by anonymous referees and by audiences at the Autonomous University of Madrid, the University of Aberdeen, and the University of Manchester.

\section{REFERENCES}

Alston, William P. 1983. What's Wrong with Immediate Knowledge? Synthese 55/1: 73-95.

Alston, William P. 1985 (1989). Concepts of Epistemic Justification, the Monist 68/1: 57-89. Reprinted in Epistemic Justification: Essays in the Theory of Knowledge, Ithaca: Cornell University Press: 81-114.

Becker, Kelly. Reliabilism, The Internet Encyclopaedia of Philosophy, ISSN 2161-0002, $\mathrm{URL}=\langle\mathrm{http}: / / \mathrm{www}$. iep.utm.edu/reliabil/>.

Bergmann, Michael 2006. Justification without Awareness: A Defence of Epistemic Externalism, Oxford: Clarendon Press.

Boghossian Paul A. 2014. What is Inference? Philosophical Studies 169/1: 1-18.

Coliva, Annalisa 2014. Moderatism, Transmission Failures, Closure, and Humean Scepticism, in Scepticism and Perceptual Justification, ed. Dodd, Dylan and Elia Zardini, Oxford: Oxford University Press: 248-71.

Conee, Earl and Richard Feldman. 1985 (2004). Evidentialism, Philosophical Studies 48/1: 15-34. Reprinted in Evidentialism: Essays in Epistemology, Oxford: Clarendon Press, 83-107.

Feldman, Richard. 2003. Epistemology, Upper Saddle River, NJ: Prentice Hall.

Firth, Roderick. 1978. Are Epistemic Concepts Reducible to Ethical Concepts? In Values and Morals: Essays in Honor of William Frankena, Charles Stevenson, and Richard Brandt, ed. Alvin Goldman and Jaegwon Kim, Dordrecht: Reidel: 215-29. 
Fumerton, Richard. 2006. Epistemology, Malden, Mass.: Blackwell.

Goldman, Alvin. 1979 (2008). What is Justified Belief? In Justification and Knowledge: New Studies in Epistemology, ed. G. Pappas, Dordrecht: D. Reidel: 1-23. Reprinted in Epistemology: An Anthology, ed. Sosa, Ernest, Jaegwon Kim, Jeremy Fantl, and Matthew McGrath, Oxford: Blackwell: 333-47.

Goldman, Alvin. 2008. Immediate Justification and Process Reliabilism, in Epistemology: New Essays, ed. Smith, Quentin Oxford: Oxford University Press: 63-81.

Ichikawa, Jonathan J. and Benjamin W. Jarvis. 2013. The Rules of Thought, Oxford: Oxford University Press.

Ichikawa, Jonathan J. and Carrie I. Jenkins forthcoming. On Putting Knowledge 'First', in Knowledge-First: Approaches to Epistemology and Mind, ed. Carter, Adam J., Emma C. Gordon, and Benjamin W. Jarvis, Oxford: Oxford University Press.

Kelly, Thomas 2016. Evidence, The Stanford Encyclopaedia of Philosophy (Winter 2016 Edition), ed. E. N. Zalta, URL = <https://plato.stanford.edu/archives/win2016/entries/evidence/>.

Kornblith, Hilary 1980. Beyond Foundationalism and the Coherence Theory, Journal of Philosophy 77/10: 567-612.

Kvanvig, Jonathan 2007. Propositionalism and the Metaphysics of Experience, Philosophical Issues 17/1: 165-78.

Kvanvig, Jonathan and Christopher Menzel 1990. The Basic Notion of Justification, Philosophical Studies 59/3: 235-61.

Lasonen-Aarnio, Maria. 2010. Is There a Viable Account of Well-Founded Belief? Erkenntnis 72/2: 205-31.

Pollock, John and Joseph Cruz 1999. Contemporary Theories of Knowledge, Lanham, Md.: Rowan \& Littlefield.

Silva, Paul 2015. On Doxastic Justification and Properly Basing One's Beliefs, Erkenntnis, 80/5: 945-55.

Smithies, Declan 2012. Moore's Paradox and the Accessibility of Justification, Philosophy and Phenomenological Research 85/2: 273-300.

Turri, John 2010. On the Relationship between Propositional and Doxastic Justification, Philosophy and Phenomenological Research 80/2: 312-26.

Vahid, Hamid 2016. A Dispositional Analysis of Propositional and Doxastic Justification, Philosophical Studies 173/11: 3133-52.

Williamson, Timothy 2000. Knowledge and its Limits, Oxford: Oxford University Press. 
Zardini, Elia 2014. Confirming the Less Likely, Discovering the Unknown: DogmatismSurd and Doubly Surd, Natural, Flat and Doubly Flat, in Scepticism and Perceptual Justification, ed. Dodd Dylan, and Elia Zardini, Oxford: Oxford University Press: $33-$ 70. 